\section{Лебедева Л.Ф.}

д-р экон. наук, профессор, руководитель Центра социальноэкономических исследований и проектов, Институт США и Канады РАН, Москва

e-mail: Liudran@mail.ru

\section{Емельянов Е.В.}

канд. экон. наук, старший научный сотрудник Центра социально-экономических исследований и проектов, Институт США и Канады РАН, Москва

e-mail: ee_79@mail.ru

\section{Lebedeva L.F.}

Doctor of Economic Sciences, Professor, Head of the Center for Social-Economic Studies and Projects, Institute for USA and Canada Studies of the Russian Academy of Sciences, Moscow

e-mail: Liudran@mail.ru

\section{Emelianov E.V.}

Candidate of Economic Sciences, Senior Researcher, Center for Social-Economic Studies, Institute for USA and Canada Studies of the Russian Academy of Sciences, Moscow

e-mail: ee_79@mail.ru

\section{Роль и место пенсионеров в американском электорате*}

\begin{abstract}
Аннотация
В статье рассматриваются факторы более активного участия в выборах пенсионеров, в сравнении с другими возрастными группами; возрастная структура электората на федеральном и штатном уровнях. В фрокусе внимания фундаментальные изменения в составе американского электората, с широким спектром различий в предпочтениях по ключевым социальным, экономическим, политическим вопросам. В США, начиная с 1980 г., на всех президентских выборах доминировали бэби бумерь (родившиеся в 1946-1964) и предшествующие им поколения, на которые приходилось большинство избирателей. Благодаря росту численности представителей более молодых поколений, в том числе избирателей латиноамериканского происхождения, электорат 2016 года стал самым разнообразным за всю историю США. Представители Миллениум (1980-1998 г.р.) и поколения X (1965-1979 г.р.), электоральные предпочтения которых существенно отличаются от старших возрастных групп, количественно превзошли группы избирателей бэби бумеров и тех, кто старше. Но ключевой вопрос в том - кто реально голосует.
\end{abstract}

Ключевые слова:

возрастная структура, электорат, постарение населения, США.

\section{The Role of Pensioners in the American Electorate}

\begin{abstract}
The article examines fundamental demographic changes in the USA that have been shifting the electorate and as a result - American politics; with wide gaps between the generations on key social, economic, political issues. The US presidential elections since 1980 were dominated by baby boomers (born 1946-1964) and prior generations, who have cast the vast majority of votes in every presidential election. The 2016 electorate has been the most diverse in the US history due to strong growth of young generations, and especially among Hispanic eligible voters. Millennials (born 1981-1998) and X generation (born 1965-1980) surpassed Baby Boomers and more old generations whose choices differ significantly in many fields; but the key problem is who really votes. The age structure of the American electorate and its influence on the election results; the role of pensioners and those, who'll retire in the nearest future, as voters at the federal and state levels are in focus.
\end{abstract}

\section{Keywords:}

population age structure, electorate, population ageing, USA.
Трансформация структуры американского электората является одним из ключевых факторов влияния на результаты выборов и, соответственно, проведение политического курса страны, что отчетливо проявилось и на прошедших в ноябре 2016 г. президентских выборах в США, где для оценки электоральной мощи той или иной группы избирателей критически важна всесторонняя оценка электората по штатам.

Глобальное постарение населения привело к тому, что в составе электората стран мира становится все больше пенсионеров и лиц предпенсионного возраста. По данным ООН (2016 г.), в мире насчитывалось около 901 млн человек в возрасте 60 лет и старше, или 12,3\% всего населения планеты. По прогнозам на 2030 г., значение этого пока- зателя возрастет до $16,5 \%$, а к 2050 г. - до $21,5 \%$. В Соединенных Штатах доля лиц 65 лет и старше в электорате 2016 г. составляла $18,9 \%$, но в ряде штатов она значительно выше: $23,9 \%$ (Флорида); 22,7\% (Мэн). В 15 штатах доля лиц 65 лет и старше превышает пятую часть числа их электората [7].

Учитывая более высокую активность пенсионеров на выборах, в сравнении с другими возрастными категориями, их влияние на исход выборов существенно выше доли в электорате. С начала текущего столетия разрыв в уровнях участия разных возрастных групп населения на выборах президента и в конгресс достигал десятков процентных пунктов. Так, на выборах в конгресс 2014 г. уровень участия американцев 65 лет и старше составлял 59,4\% против $23,1 \%$ среди возрастной группы 18-34 года [11].

\footnotetext{
* Статья подготовлена при финансовой поддержке Фонда РГНФ, проект 15-07-00002 (а) «Роль государственной политики в повышении эффективности использования пенсионных накоплений как инвестиционного ресурса в эпоху глобализации»-
} 
Для кандидатов в Президенты США, согласно Конституции, установлен лишь нижний предел по возрасту. Президентом США может стать только гражданин США по рождению, старше 35 лет, постоянно проживающий в США не менее 14 последних лет. В большинстве своем президенты США были избраны в возрасте до 60 лет; самым молодым президентом в истории США был Джон Кеннеди, ставший президентом в 43 года, а самым пожилым Рональд Рейган, избранный в возрасте 69 лет, переизбранный в возрасте 73 лет. В 2016 г. оба основных кандидата в президенты на выборах 2016 г. (Х. Клинтон и Д. Трамп) были в возрасте старше 65 лет. Победил и стал 45-м президентом США Д. Трамп. Кто же обеспечил эту победу? Какие группы американского общества?

\section{Состав и динамика электората}

Президентские выборы, состоявшиеся в США в ноябре 2016 г., показали необходимость переосмысления реалий на всех уровнях и во всех ветвях власти. Потребность в изменениях достигла в американском обществе столь высокого уровня, что практически стала доминантой результатов голосования 8 ноября 2016 г. на фоне поляризации электората.

За Д. Трампа проголосовали $58 \%$ из числа белых избирателей (против $37 \%$ за Х. Клинтон) и $21 \%$ - из представителей расово-этнических меньшинств (против 74\% за Х. Клинтон). Столь же значительным оказался разрыв в предпочтениях и по возрастным группам американского общества: за Д. Трампа отдали голоса $53 \%$ избирателей в возрасте 45 лет и старше ( $44 \%$ - за Х. Клинтон) и $37 \%$ самой молодой группы избирателей 18-29 лет (55\% - за Х. Клинтон) (см. табл. 1).

Результаты опросов в период последней президентской кампании также показали, что республиканцы имели заметную поддержку среди белого большинства, главным образом среди мужчин, в то время как демократы пользовались доминирующей поддержкой женщин и этнических меньшинств [5]. В 2016 г. американцы выбирали президента из двух самых непопулярных кандидатов за всю историю страны. Согласно традиционно проводимому накануне выборов опросу Gallup (проведен 2-5 ноября на всей территории США), уровень негативной оценки Д. Трампа составил $61 \%$, а Х. Клинтон $52 \%$, в сравнении с аналогичными оценками Дж. Кеннеди (опрос 18-23 октября 1960 г.) - 21\%, Р. Рейгана (опрос 10-13 октября 1980 г.) $-37 \%$, Б. Обамы $-37 \%$ (27-28 октября 2012 г.) [12].

Усталость от агрессивной, смещенной на личный компромат президентской кампании сказалась и на
Таблица 1

За кого голосовали группы избирателей

\begin{tabular}{|l|l|l|}
\hline $\begin{array}{l}\text { Проголосовавшие группы } \\
\text { избрателей }\end{array}$ & За Д. Трампа & За Х. Клинтон \\
\hline В возрасте 18-29 лет & 37 & 55 \\
\hline В возрасте 30-44 лет & 42 & 50 \\
\hline В возрасте 45-64 лет & 53 & 44 \\
\hline В возрасте 65 лет и старше & 53 & 45 \\
\hline Мужчины & 53 & 41 \\
\hline Женщины & 42 & 54 \\
\hline Белые & 58 & 37 \\
\hline Чернокожие & 8 & 88 \\
\hline Испаноязычные & 29 & 65 \\
\hline Азиатского происхождения & 29 & 65 \\
\hline Другие & 37 & 56 \\
\hline
\end{tabular}

Источник: составлено по данным: [13].

Таблица 2

Группы американского электората по возрасту 2016 г.

\begin{tabular}{|l|l|l|l|}
\hline Группы электората & $\begin{array}{c}\text { Возраст в } \\
\text { 2016 г., } \\
\text { лет }\end{array}$ & $\begin{array}{c}\text { Численность } \\
\text { возрастной } \\
\text { группы в } \\
\text { 2016 г., } \\
\text { млн человек }\end{array}$ & $\begin{array}{c}\text { Доля } \\
\text { возрастной } \\
\text { группы } \\
\text { населения в } \\
\text { электорате, } \\
\text { \% }\end{array}$ \\
\hline $\begin{array}{l}\text { Родившиеся } \\
\text { В 1981-1998 гг. }\end{array}$ & $18-35$ & 69,2 & 30,4 \\
\hline $\begin{array}{l}\text { Родившиеся } \\
\text { в 1965-1980 гг. }\end{array}$ & $36-51$ & 56,8 & 25,5 \\
\hline $\begin{array}{l}\text { Родившиеся } \\
\text { в 1946-1964 гг. }\end{array}$ & $52-70$ & 69,7 & 31,3 \\
\hline $\begin{array}{l}\text { Родившиеся } \\
\text { в 1945 г. и ранее }\end{array}$ & 71 и старше & 28,3 & 12,7 \\
\hline
\end{tabular}

Источник: составлено по данным: [9].

общей активности избирателей - наиболее низкой $(55,4 \%)$ с 2000 г. Например, в 2008 г., когда президент также избирался в ожидании больших перемен, после восьми лет пребывания у власти предшественника, доля тех, кто участвовал в голосовании, достигла $63,7 \%$ [11].

В условиях существенных изменений, происходящих с начала текущего столетия в возрастном и расово-этническом составе электората, именно традиционно более высокая явка на президентских выборах белых американцев старших возрастных групп (в разные годы достигала от 65 до $72 \%$ среди лиц 65 лет и старше) стала критически важной для результатов прошедших в прошлом году выборов президента.

Электоральная мощь пенсионеров возрастала по мере взросления поколения бэби-бумеров, родив- 


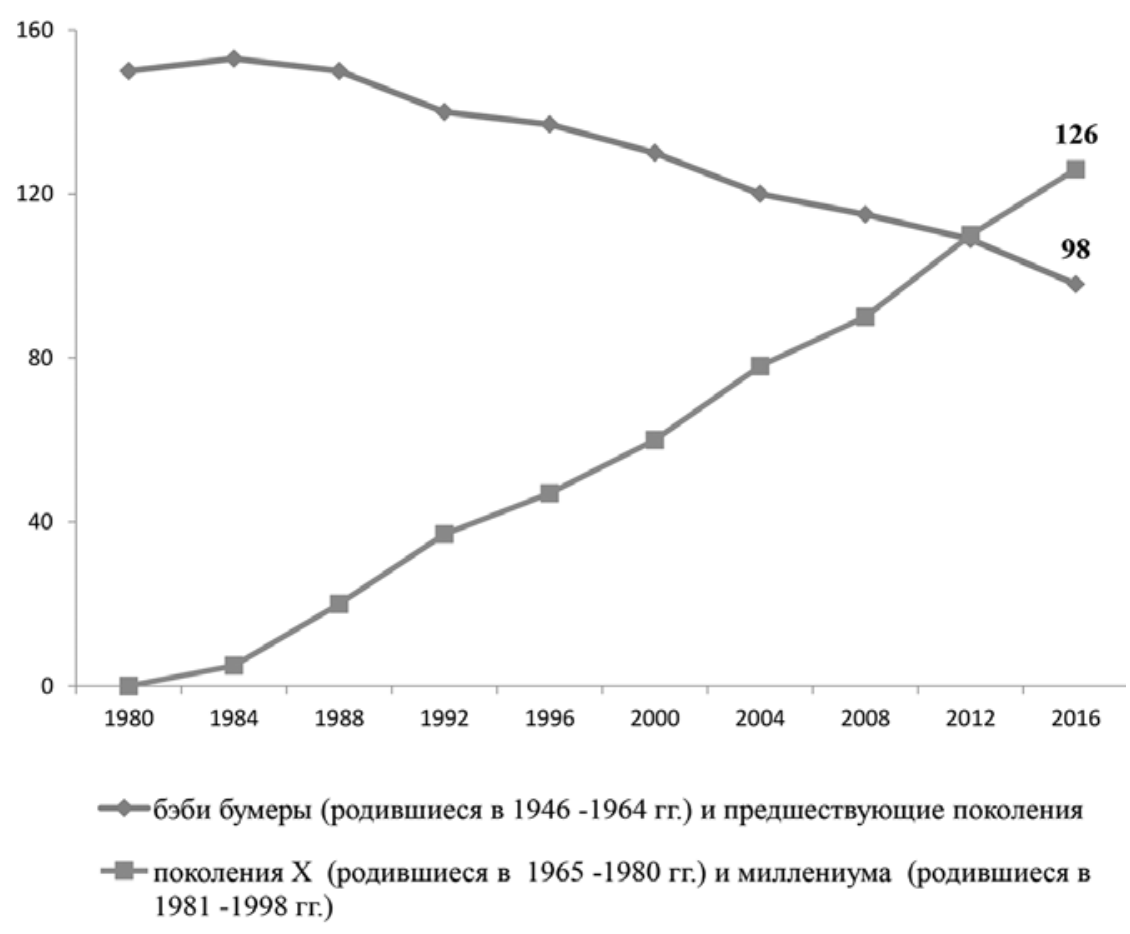

Рис. 1. Население США в возрасте 18 лет и старше (млн человек) Источник: [9]

шихся в 1946-1964 гг. Начиная с 1980 г., бэби-бумеры (1946-1964 г.р.) и предшествующие им поколения доминировали на всех президентских выбоpax [7]. Именно на эти возрастные группы приходилось большинство проголосовавших американцев. Если в период президентских выборов 2012 г. они еше превышали по численности группы родившихся в 1965-1980 гг. (поколение Х) и в 1981-1998 гг. (поколение Миллениума), то в 2016 г. эти две возрастные группы избирателей количественно превзошли группы старших возрастов.

Динамика численности бэби-бумеров свидетельствует о том, что эта группа американского электората уменьшается: с 72,9 млн человек в 2004 г. до 69,7 млн человек в 2016 г. [9]. В результате, по состоянию на июль 2016 г., бэби-бумеры и более старшие поколения составляли 44\% (98 млн человек) американского электората, а родившиеся в 19651998 гг., соответственно, - 56\% (126 млн человек) (см. рис. 1).

Таким образом, поколение $\mathrm{X}$ и поколение Миллениума, превысив по численности избирателей старших возрастов, формально получили новые возможности влиять на исход выборов. Но ключевой вопрос в том, кто реально голосует. Учитывая обычно более высокую активность пенсионеров на выборах, в сравнении с другими возрастными ка- тегориями, их влияние на исход выборов превышает долю в электорате.

На прошедших 8 ноября 2016 г. выборах пенсионеры и те, кто в ближайшем будущем выйдет на пенсию, оставались, благодаря своей высокой явке, наиболее влиятельной электоральной силой.

Прогнозируемая динамика состава населения показывает, что и в следующем десятилетии поколение бэби-бумеров будет ключевым фактором увеличения доли лиц 65 лет и старше - до 19\% в 2030 г. Именно эта часть населения, как было отмечено, традиционно показывает более высокий уровень участия в выборах, будь то президентские или выборы в конгресс.

В течение второй половины XX в. пенсионеры, благодаря государственной программе пенсионного страхования, стали и остаются одной из наиболее социально защищенных групп населения в США [4]. В начале 2010-х гг., те из них, кто родился во второй половине 1940-х гг., достигли возраста выхода на пенсию. Согласно закону о социальном обеспечении (1935 г.), пенсионный возраст был установлен на уровне 65 лет. В результате последующего поэтапного повышения возраста выхода на пенсию сегодня для первых бэби-бумеров он составляет 66 лет [1]. За последние полвека доля лиц 65 лет и старше, имеющих доходы ниже черты бед- 


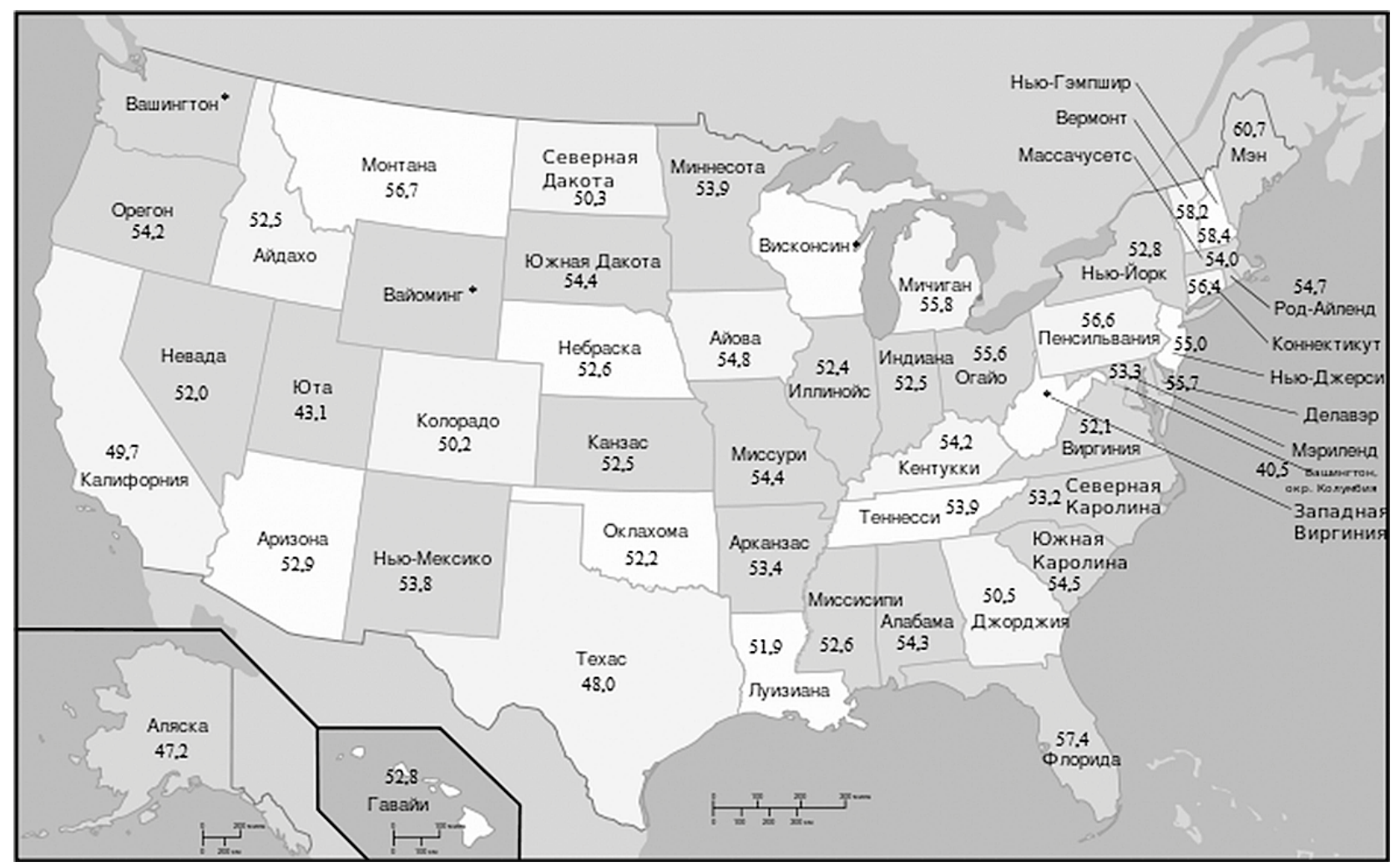

Рис. 2. Доля избирателей в возрасте 45 лет и старше по штатам, \% Источник: рассчитано по: [14]

ности, существенно снизилась - до $8,8 \%$, в сравнении с 13,5\% - для всех возрастных групп (2015 г.). И те, кто приближается к выходу на пенсию, отнюдь не хотят возможных ограничений, ущемляющих их будущие доходы на пенсии, при смене власти; поэтому они так же, как и уже достигшие пенсионного возраста, активно участвуют в голосовании.

Заинтересованность американцев пенсионного и предпенсионного возрастов в исходе выборов и изменениях в политическом курсе связана в том числе и с ростом их экономической активности [2]. По данным специального обследования Бюро трудовой статистики США, доля лиц 55 лет и старше в рабочей силе составляла в начале 2010-х гг. около $21 \%$, а по прогнозу на 2022 г., возрастет до 25\% [6]. Трудовая активность пенсионеров объективно повышает их заинтересованность в том, какая экономическая политика будет проводиться, какие изменения возможны в сфере налогообложения и т.п.

Не меньший интерес к результатам выборов проявляют и пенсионеры, а также американцы предпенсионного возраста, которые являются владельцами малого бизнеса или собираются ими стать. Среди владельцев малых предприятий основную часть (51\%) составляют как раз те, кто достиг 50 лет и старше. Американцы предпенсионного и пенсионного возрастов всегда были очень активны как предприниматели, при этом за годы после глобального кризиса их доля даже возросла.

Усиливается их интерес к возможным переменам в экономической политике: «...в силу специфики функционирования малых предприятий, связанной с высокой степенью риска, мобильностью рабочей силы, занятые в этом секторе проявляют растущий интерес к дополнительным (относительно обязательной государственной программы пенсионного страхования) частным пенсионным планам» [3]. Эта группа населения заинтересована в том, какие дополнительные льготы и возможности могут быть им предоставлены новой администрацией по открытию пенсионных планов, инвестированию накоплений и (или) введены ограничения в данной области [8].

Так, согласно опросу владельцев малых предприятий в апреле 2016 г., около половины из принявших в нем участие уверены, что результаты президентских выборов окажут значительное влияние на их бизнес [10].

Отметим, что американский электорат в целом становится все более разнообразным по расово- 
этническому признаку, особенно это касается более молодых поколений. Если посмотреть на динамику населения по расово-этническому признаку с начала текущего столетия, по годам президентских выборов, то в период с 2000 г. не изменилась лишь доля чернокожего населения - $12 \%$. Доля белых в общем числе избирателей уменьшилась с 78\% (2000 г.) и 73\% (2008 г.) до 69\% (2016 г.); доля испаноязычного населения возросла с 7\% и 9\%, соответственно, до $12 \%$; а выходцев из Азии - с 2\% (2000 г.), $3 \%$ (2008 г.) до 4\% (2016 г.). Бэби-бумеров остается значительно больше среди белого населения (27\%), чем среди меньшинств (17\%). Среди чернокожего населения бэби-бумеры составляют $21 \%$, среди выходцев из Азии - $20 \%$, и меньшего всего - среди испаноязычного населения - 14\% [9].

\section{Результаты выборов определяются в штатах}

Рассмотрение возрастного состава электората, в силу установленной процедуры выборов в США, крайне важно не только в целом по стране, но и на уровне штатов. Почти 230 лет назад, в сентябре 1787 г., в США для избрания президента была утверждена Коллегия выборшиков. В большинстве штатов голоса всех выборщиков автоматически получает тот кандидат, который набирает простое большинство голосов избирателей штата. При доле избирателей в возрасте 65 и старше в составе американского электората $18,9 \%$, в ряде штатов она значительно выше, например, 23,9\% (Флорида), 22,7\% (Мэн), 21,2\% (Пенсильвания), 21,0\% (Делавэр) [14].

При этом определяющими исход выборов являются так называемые колеблющиеся, или неопределившиеся штаты - swing states, в которых голоса переходят от демократов к республиканцам и от республиканцев к демократам. Результаты выборов 2016 г. фактически зависели от голосования в нескольких штатах, в том числе Флорида, Пенсильвания, Огайо, Северная Каролина, Вирджиния, Колорадо, Айова, Невада, Нью-Гэмпшир.

Кандидат в президенты, одержавший победу в штате Флорида, становился президентом США на
10 из последних 11 президентских выборов (включая выборы 2016 г.). Исключением был 1992 г., когда жители Флориды проголосовала за Дж. Бушастаршего, но президентом стал Б. Клинтон.

В штате Пенсильвания, где в 2016 г. 21,2\% числа избирателей были в возрасте 65 лет и старше, начиная с 1992 г. большинство голосов получали демократы. Начиная с июля 2016 г., по результатам опросов, X. Клинтон опережала Д. Трампа, но победил и в этом штате Д. Трамп.

В штате Огайо, где в 2016 г. 20,1\% числа избирателей в возрасте 65 лет и старше, начиная с 1944 г. лишь один раз большинство голосов получил кандидат, потерпевший на выборах поражение(1960 г.). Д. Трамп и здесь одержал победу.

Стоит обратить внимание и на то, что во многих штатах преобладали избиратели 45 лет и старше, а в ряде штатов, от которых зависел исход выборов, доля избирателей данной возрастной группы достигала в Нью-Гэмпшире 58,4\% состава избирателей, во Флориде $-57,4 \%$, в Пенсильвании $-56,6 \%$ (см. рис. 2).

Победив, прежде всего благодаря поддержке преимущественно белого населения в возрасте 45 лет и старше, при проведении своей политики Д. Трампу придется учитывать меняющийся состав американского общества со всеми доставшимися в наследство проблемами. Процесс «перезагрузки» приоритетов в обществе, «расколотом» по расовоэтнической, гендерной, возрастной принадлежности, предстоит особенно сложный, учитывая принципиально разные подходы, с широким спектром различий в предпочтениях по ключевым социальным, экономическим, политическим вопросам, представителей демократов и пришедшей к власти администрации Д. Трампа. Результаты выборов президента в США показали, что от нового президента ждут перемен. У Д. Трампа будет республиканский Конгресс, однако в силу расхождений и внутри республиканской партии это не снимает ограничений, с которыми придется считаться, на пути реализации его платформы практически по всем направлениям.

\section{Литература}

1. Аксенов П.А. Роль государства в социальном обеспечении пенсионеров: повестка XXI века [Текст] / П.А. Аксенов, Л.Ф. Лебедева, С.В. Емельянов. - М.: Институт Соединенных Штатов Америки и Канады РАН, 2015. $-45 \mathrm{c}$.

\section{References}

1. Aksenov P.A. Lebedeva L.F., Emel'yanov S.V. Rol' gosudarstva $v$ sotsial'nom obespechenii pensionerov: povestka XXI veka. Institut Soedinennykh Shtatov Ameriki i Kanady RAN [The role of the state in social security pensioners: the agenda of the XXI century. United States Institute of America and Canada]. Moscow, 2015. 45 p. 
2. Емельянов E.В. Поколение бэби-бума не уходит на пенсию [Текст] / Е.В. Емельянов, Н.С. Фризяк // СШАКанада: ЭПК. - 2015. - № 9(549). - С. 90-97.

3. Емельянов С.В. Стратегии пенсионного обеспечения в секторе малого бизнеса США [Текст] / С.В. Емельянов, А.В. Шербина // США - Канада: ЭПК. - 2015. - № 9. - С. 82-89.

4. Развитие пенсионного обеспечения в начале XXI века: мировые тенденции и национальные особенности [Текст]. - М.: ИСКРАН, 2015. - 168 с.

5. Травкина Н.М. Особенности президентской кампании 2016 г. в США - случайная аномалия или предвестник турбулентности? [Текст] / Н.М. Травкина // Перспективы. - 2016. - № 3 (7). - С. 19-34.

6. Bureau of labor Statistics. December 19, 2013.

7. Current Population Survey. W., April 2016.

8. Lebedeva L.F., Aksenov P.A., Yemelyanov S.V., Yemelyanov E. $V$. The Pension Funds' Investment Regulation at the Beginning of the 21st Century: 62 Comparative Analysis of Approaches of the USA, Canada, and the EU-15 Countries // Mediterranean Journal of Social Sciences. 2015. Vol. 6, no. 4, August. Pp. 155-162. (In English).

9. Millennials match baby-boomers. Pew Research Center. http://www.pewresearch.org/fact-tank/2016/05/16 (дата обращения: 24.10.2016).

10. Small-Business Owners Say Candidates Fail to Address Issues. Gallup poll. May 4, 2016. http://www. Gallup.com/ poll/191336/ (дата обращения: 22.10.2016).

11. Thom File. Who Votes? Congressional Elections and the American Electorate. Bureau census. W., July 2015.

12. Trump and Clinton Finish With Historically Poor Images. Gallup poll. November 08.2016. http://www.gallup.com/ poll/197231/trump-clinton-finish-historically-poor-images.aspx?g_source=Election\%202016\&g_medium=lead\&g_campaign=tiles (дата обращения: 11 ноября 2016).

13. US politics election. http://www.nytimes.com/interactive/2016/11/08/us/politics/election-exit-polls.html?_r=0 (дата обращения: 11.11.2016).

14. Voting Age population. US Bureau Census, April 16.2016.
2. Emel'yanov E.V., Frizyak N.S. Pokolenie Bebi - Buma ne ukhodit na pensiyu [Generation Baby - Boomers are not retiring]. SShA-Kanada: EPK [US-Canada EPA]. 2015, I. 9(549), pp. 90-97.

3. Emel'yanov S.V., Shcherbina A.V. Strategii pensionnogo obespecheniya v sektore malogo biznesa SShA. SShA - Kanada: $E P K$ [Strategy pension sector in US Small Business Administration. US - Canada: EPA]. 2015, I. 9, pp. 82-89.

4. Razvitie pensionnogo obespecheniya $v$ nachale XXI veka: mirovye tendentsii i natsional'nye osobennosti [Development of the pension at the beginning of the XXI century: global trends and national characteristics]. Moscow, ISKRAN Publ., 2015. 168 p.

5. Travkina N.M. Osobennosti prezidentskoy kampanii $2016 \mathrm{~g}$. v SShA - sluchaynaya anomaliya ili predvestnik turbulentnosti? - Perspektivy [Features of the presidential campaign of 2016 in the United States - a random anomaly or a harbinger of turbulence? - Prospects]. 2016, I. (7), pp. 19-34.

6. Bureau of labor Statistics. December 19, 2013.

7. Current Population Survey. W., April 2016.

8. Lebedeva L.F., Aksenov P.A., Yemelyanov S.V, Yemelyanov E.V. The Pension Funds' Investment Regulation at the Beginning of the 21st Century: 62 Comparative Analysis of Approaches of the USA, Canada, and the EU-15 Countries // Mediterranean Journal of Social Sciences. 2015. Vol. 6, no. 4, August. P. 155-162. (In English).

9. Millennials match baby-boomers. Pew Research Center. Available at: http://www.pewresearch.org/facttank/2016/05/16 (accessed 24 October 2016).

10. Small-Business Owners Say Candidates Fail to Address Issues. Gallup poll. May 4, 2016. Available at: http://www. Gallup.com/poll/191336/ (accessed 22 October 2016).

11. Thom File. Who Votes? Congressional Elections and the American Electorate. Bureau census. W., July 2015.

12. Trump and Clinton Finish With Historically Poor Images. Gallup poll. November 08. 2016. Available at: http://www. gallup.com/poll/197231/trump-clinton-finish-historically-poor-images.aspx?g_source=Election\%202016\&g_medium=lead\&g_campaign=tiles $($ accessed 11 November 2016).

13. US politics election. http://www.nytimes.com/interactive/2016/11/08/us/politics/election-exit-polls.html?_r=0 (accessed 11 November 2016).

14. Voting Age population. US Bureau Census, April 16.2016. 